\title{
miR-20a suppresses Treg differentiation by targeting Map3k9 in experimental autoimmune encephalomyelitis
}

\author{
Yishu Wang®, Chong Xie, Yaying Song, Weiwei Xiang, Jing Peng, Lu Han, Jie Ding and Yangtai Guan*
}

\begin{abstract}
Background: Experimental autoimmune encephalomyelitis (EAE) is a model for inflammatory demyelinating diseases of the central nervous system (CNS), a group of autoimmune diseases characterized by inflammatory infiltration, demyelination, and axonal damage. miR-20a is dysregulated in patients with CNS inflammatory demyelinating diseases; however, the function of miR-20a remains unclear. In this study, we intended to explore the role of miR-20a in EAE.

Methods: The expression of miR-20a was detected by quantitative real-time PCR (qRT-PCR) in EAE mice and patients with MOG antibody-associated demyelinating diseases. CD4 ${ }^{+}$T cells of EAE mice were sorted, stimulated, and polarized with miR-20a knockdown. Activation and differentiation of $\mathrm{CD}^{+} \mathrm{T}$ cells were analyzed by flow cytometry. The expression of target gene Map3k9 was detected by qRT-PCR and western blot experiments. The binding of miR-20a to the 3' UTR of Map3k9 was tested by luciferase assays. The feasibility of miR-20a as a therapeutic target to alleviate the severity of EAE was explored by intravenous administration of miR-20a antagomirs to EAE mice.

Results: miR-20a was upregulated in splenocytes and lymph node cells, CD4 ${ }^{+} \mathrm{T}$ cells, and spinal cords of EAE mice. Moreover, miR-20a knockdown did not influence the activation of antigen-specific $\mathrm{CD}^{+} \mathrm{T}$ cells but promoted their differentiation into Treg cells. Map3k9 was predicted to be a target gene of miR-20a. The expressions of Map3k9 and miR-20a were negatively correlated, and miR-20a knockdown increased the expression of Map3k9. In addition, miR-20a binded to the 3' UTR of Map3k9, and simultaneous knockdown of miR-20a and Map3k9 counteracted the enhanced differentiation of Tregs observed when miR-20a was knocked down alone. Furthermore, injection of miR20a antagomirs to EAE mice reduced the severity of the disease and increased the proportion of Treg cells in peripheral immune organs.
\end{abstract}

Conclusions: miR-20a suppresses the differentiation of antigen-specific CD4 ${ }^{+} \mathrm{T}$ cells into Tregs in EAE by decreasing the expression of Map3k9. miR-20a antagomirs alleviate EAE, suggesting a new therapy for EAE and CNS inflammatory demyelinating diseases.

Keywords: miR-20a, Map3k9, Regulatory T cell, Experimental autoimmune encephalomyelitis, Inflammatory demyelinating diseases of the central nervous system

*Correspondence: yangtaiguan@sina.com

Department of Neurology, Renji Hospital, Shanghai Jiaotong University

School of Medicine, 160 Pujian Road, Shanghai 200127, China

\section{Background}

Inflammatory demyelinating diseases of the central nervous system (CNS) are a group of autoimmune diseases targeting oligodendrocytes or support cells (such as astrocytes); these diseases are characterized by inflammatory infiltration, demyelination, and axonal damage, and 
examples include multiple sclerosis (MS), neuromyelitis optica spectrum disorder (NMOSD), and myelin oligodendrocyte glycoprotein (MOG) antibody-associated demyelinating disease [1-4]. Millions of patients worldwide suffer various symptoms, including visual, motor, and sensory disturbances [5], while therapies for these diseases are still quite limited.

To date, the exact mechanism resulting in CNS inflammatory demyelinating diseases is still unclear, and both innate and adaptive immune cells have been reported to be involved [6-8]. Most studies on the pathogenesis of CNS inflammatory demyelinating diseases have been carried out on an experimental autoimmune encephalomyelitis (EAE) model. EAE used to be the most widely accepted model for MS $[9,10]$; however, in recent years, a growing number of studies have demonstrated that the disease which EAE reproduces is MOG antibodyassociated demyelinating disease [11, 12]. Although the mechanism for the development of EAE is uncertain, autoreactive $\mathrm{CD} 4^{+} \mathrm{T}$ cells are generally recognized as the main cells mediating myelin damage $[13,14]$. In the EAE model, IFN- $\gamma$-producing T helper (Th) 1 and IL-17A-producing Th17 cells are considered crucial effector cells $[9,10,15]$. They infiltrate into CNS lesions in both EAE mice and patients $[9,10]$, and transplanted autoreactive Th1 and Th17 cells can induce EAE symptoms in wildtype (WT) recipient mice. They activate astrocytes and microglia and secrete proinflammatory cytokines such as IFN- $\gamma$, IL-17A/F, and GM-CSF to cause tissue damage $[5,9,10,13,14,16-18]$. In contrast, adoptive transfer of $\mathrm{CD}^{2} 5^{+} \mathrm{Foxp}^{+}{ }^{+}$regulatory $\mathrm{T}$ (Treg) cells is able to ameliorate EAE symptoms, whereas the depletion of Tregs worsens the disease [19], indicating the essential role of Tregs in the suppression of the autoimmune response and maintenance of immune tolerance.

MicroRNAs (miRNAs) are a class of non-coding RNA molecules that play a necessary role in cell differentiation, proliferation, development, and survival by binding to the complementary 3' UTR of target mRNAs, resulting in mRNA translational inhibition or degradation [20, 21]. In addition, miRNAs are frequently transcribed together as polycistronic primary transcripts that are processed into multiple individual mature miRNAs that are coordinated in function [22]. The miR-17-92 cluster is a typical polycistronic miRNA gene encoding 6 miRNAs (miR-17, miR-18a, miR-19a, miR-20a, miR-19b-1, and miR-92a-1). Identified in 2005, miR-17-92 was initially distinguished as an 'oncomir' because of its oncogenic nature in hematopoietic malignancies, medulloblastomas, lung cancer, colon cancer, and pancreatic cancer [23, 24]. However, in recent years, the effects of miR-17-92 on $\mathrm{CD}^{+} \mathrm{T}$ cells have been gradually revealed. Overexpressing miR-17-92 in $\mathrm{CD} 4^{+} \mathrm{T}$ cells results in a higher percentage of cells in the S phase when stimulated with antigen [25] and a lower percentage of cells in the Sub-G0 phase when stimulated with anti-CD3 [26], indicating that miR-17-92 promotes proliferation and survival of activated $\mathrm{CD} 4^{+}$ $\mathrm{T}$ cells. In addition, naïve $\mathrm{CD} 4^{+} \mathrm{T}$ cells deficient in miR17-92 differentiate into fewer Th1 and Th17 cells but more induced Treg (iTreg) cells, suggesting the important role of miR-17-92 in the differentiation of $\mathrm{CD} 4^{+} \mathrm{T}$ cells $[27,28]$. Furthermore, individual miRNAs of miR17-92 are upregulated or downregulated in the peripheral blood of patients, and the expressions of the miRNAs revert to normal levels with medical treatment or during remission [29-34]. In general, accumulating evidence has demonstrated that miR-17-92 is an essential regulator of $\mathrm{CD}^{+} \mathrm{T}$ cells and that the expression of miR-17-92 is altered in patients with CNS inflammatory demyelinating diseases; however, the precise role of miR-17-92 in the development of diseases and whether miR-17-92 affects diseases by modulating $\mathrm{CD} 4^{+} \mathrm{T}$ cells remain unknown.

In this study, we focused on miR-20a, a member of the miR-17-92 cluster. We first detected the upregulation of miR-20a in EAE mice and patients with MOG antibodyassociated demyelinating diseases. We then explored the role of miR-20a in the activation and differentiation of antigen-specific $\mathrm{CD} 4^{+} \mathrm{T}$ cells in EAE. In addition, we found that Map3k9 (mitogen-activated protein kinase kinase kinase 9) is the target gene of miR-20a in $\mathrm{CD}_{4}^{+} \mathrm{T}$ cells of EAE mice, as confirmed by luciferase assays and functional validation. Furthermore, we tested the therapeutic potential of miR-20a antagomirs and found that miR-20a antagomirs alleviated EAE.

\section{Methods}

Mice

C57BL/6 mice were purchased from Lingchang Biotechnology Company (Shanghai, China). The animals were housed and fed in a specific pathogen-free animal facility at the Experimental Animal Center of Renji Hospital. 8 to 12-week-old female mice were used for all experiments. Experiments were performed in accordance with the guidelines for animal care and were approved by the Animal Ethics and Welfare Committee of Renji Hospital affiliated to Shanghai Jiaotong University School of Medicine (Shanghai, China).

\section{EAE induction and evaluation}

For EAE induction, myelin oligodendrocyte glycoprotein residues 35-55 (MOG $\left.{ }_{35-55}\right)$ peptide (Met-Glu-Val-GlyTrp-Tyr-Arg-Ser-Pro-Phe-Ser-Arg-Val-Val-His-LeuTyr-Arg-Asn-Gly-Lys, GL Biochem Ltd, Shanghai, China) dissolved in PBS was emulsified with complete Freund's adjuvant (CFA), which is composed of incomplete Freund's adjuvant and Mycobacterium tuberculosis 
$H 37 R a$ (BD Difco, MI, USA). The final concentrations of $\mathrm{MOG}_{35-55}$ peptide and Mycobacterium tuberculosis $H 37 R a$ in the $\mathrm{MOG}_{35-55} / \mathrm{CFA}$ emulsion were $1.5 \mathrm{mg} /$ $\mathrm{ml}$ and $4 \mathrm{mg} / \mathrm{ml}$, respectively. Each mouse was injected subcutaneously with $200 \mu \mathrm{l} \mathrm{MOG}_{35-55} / \mathrm{CFA}$ emulsion near bilateral inguinal lymph nodes. In addition, $200 \mathrm{ng}$ pertussis toxin (PTX; Millipore, Billerica, MA, USA) was administered intraperitoneally on the day of immunization (Day 0) and again 2 days later (Day 2).

Clinical assessment of EAE was performed daily after disease induction according to the following scoring system: 0 , no clinical symptoms; 0.5 , limp tail; 1 , paralyzed tail; 1.5 , hindlimb weakness, uncoordinated movement; 2, hindlimb paresis; 2.5 , paralysis of one hindlimb; 3 , paralysis of one hindlimb with the other hindlimb weakness; 3.5 , complete paralysis of both hindlimbs; 4 , hindlimb paralysis with forelimb paresis; 4.5 , forelimb and hindlimb paralysis; and 5, moribund state or death.

\section{RNA extraction, reverse transcription, and quantitative real-time PCR}

Total RNA (including mRNA and small RNA) was extracted from cell pellets and spinal cord tissues using an RNeasy Mini Kit (QIAGEN, Hilden, Germany) according to the manufacturer's instructions. Reverse transcription was performed using a Mir- $\mathrm{X}^{\mathrm{TM}}$ miRNA First Strand Synthesis Kit (Cat. 638315, Takara, Shiga, Japan) for miRNA and a PrimeScript ${ }^{\mathrm{TM}}$ RT reagent Kit (Cat. RR037A, Takara, Shiga, Japan) for mRNA. For relative quantitative real-time PCR (qRT-PCR), SYBR Advantage qPCR Premix (Cat. 639676, Takara, Shiga, Japan) and SYBR Green master mix (Cat. RR820A, Takara, Shiga, Japan) were used for the cDNA of miRNA and mRNA following the manufacturer's instructions. The reactions were performed in a LightCycler 480 System (Roche, Basel, Switzerland), and U6 snRNA and $\beta$-actin were used as endogenous controls of miRNA and mRNA, respectively. The expression of the miRNAs and mRNAs normalized to the endogenous control were calculated using the $2^{-}$ $\triangle \triangle \mathrm{CT}$ method and are presented as the fold change relative to the control group. The primer sequences applied in this study are listed in Additional file 1: Table S1.

\section{Isolation of $\mathrm{CD}^{+} \mathrm{T}$ cells}

For isolation of $\mathrm{CD}_{4}^{+} \mathrm{T}$ cells from EAE and control mice, mice were sacrificed at the peak stage of disease after immunization, and the spleens and lymph nodes were harvested. The tissues were ground on a $40-\mu \mathrm{m}$ strainer to prepare single-cell suspensions. After lysis of erythrocytes, splenocytes and lymph node cells were pelleted to isolate $\mathrm{CD} 4^{+} \mathrm{T}$ cells by magnetic bead cell sorting (MACS) according to the manufacturer's instructions (Miltenyi Biotech, Bergisch Gladbach, Germany).
In brief, the cell pellet was resuspended in MACS buffer and incubated with biotin-antibody cocktail for $5 \mathrm{~min}$ at $2-8{ }^{\circ} \mathrm{C}$. After that, anti-biotin microbeads were added, for isolation of naïve $\mathrm{CD} 4^{+} \mathrm{T}$ cells, CD44 microbeads were also added. Then the mixture was incubated for $10 \mathrm{~min}$ at $2-8{ }^{\circ} \mathrm{C}$. After incubation, the cells were separated with an LS Column in a MACS Separator, and the unlabeled cells in the flow-through, which are the $\mathrm{CD} 4^{+}$ $\mathrm{T}$ cells, were collected.

\section{Transfection of antagomirs and small interfering RNAs}

For miR-20a and Map3k9 silencing, a chemically modified ssRNA oligonucleotide, miR-20a antagomir, was applied to knock down the expression of miR-20a, and small interfering RNA (siRNA) duplexes of Map3k9 were used for the knockdown of Map3k9. The antagomirs, siRNAs, and negative control were synthesized by GenePharma Ltd. (Shanghai, China), and their sequences were as follows. miR-20a antagomir: 5'-CUA CCUGCACUAUAAGCACUUUA-3'; Map3k9 siRNA: sense, 5'-GGACCAGCUAACGACUAUATT -3', antisense, 5'- UAUAGUCGUUAGCUGGUCCTT -3'; NC antagomir: 5'- CAGUACUUUUGUGUAGUACAA -3'. The $\mathrm{CD} 4^{+} \mathrm{T}$ cells isolated from splenocytes and lymph node cells were transfected with the miR-20a antagomirs (200 nM), Map3k9 siRNA (400 nM), or negative control using Entranster ${ }^{\mathrm{TM}}$-R4000 (Cat. 4000-3, Engreen, Beijing, China) and harvested $12 \mathrm{~h}$ after transfection for the following experiments.

\section{Treg polarization of naïve or MOG-specific $\mathrm{CD}^{+} \mathrm{T}$ cells in vitro}

Cells were cultured in complete RPMI medium (10\% fetal bovine serum, 2 mM GlutaMAX ${ }^{\mathrm{TM}}$ Supplement (Thermo Fisher Scientific, Waltham, MA, USA), 25 mM HEPES, $55 \mu \mathrm{M}$ 2-mercaptoethanol, mycoplasma prophylactic reagent, and penicillin/streptomycin) in 24-well plates $\left(3 \times 10^{6}\right.$ cells $\left./ \mathrm{ml}\right)$. To induce the differentiation of naïve $\mathrm{CD}^{+} \mathrm{T}$ cells into Treg cells, an anti-CD3e (145-2C11, $10 \mu \mathrm{g} / \mathrm{ml}$, Thermo Fisher Scientific, Waltham, MA, USA) antibody and anti-CD28 antibody $(37.51,10 \mu \mathrm{g} /$ $\mathrm{ml}$, Thermo Fisher Scientific, Waltham, MA, USA) were used to stimulate the cells, and recombinant mouse IL-2 (20 ng/ml, R\&D Systems, Minneapolis, MN, USA) and mouse TGF- $\beta 1$ (20 ng/ml, PeproTech, Rocky Hill, NJ, USA) were added to the medium for Treg polarization. Naïve $C D 4^{+} \mathrm{T}$ cells stimulated with anti-CD3 and antiCD28 antibodies without IL-2 or TGF- $\beta 1$ were cultured as a control. The cells were polarized for 4 days before harvest.

To polarize MOG-specific $\mathrm{CD} 4^{+} \mathrm{T}$ cells into Treg cells, $\mathrm{CD} 4^{+} \mathrm{T}$ cells isolated from EAE were mixed with the remaining splenocytes and lymph node cells after 
transfection. $\mathrm{MOG}_{35-55}(40 \mu \mathrm{g} / \mathrm{ml}$, GL Biochem Ltd, Shanghai, China) was used to stimulate the cells in the culture medium, and recombinant mouse IL-2 (20 ng/ $\mathrm{ml}, \mathrm{R} \& \mathrm{D}$ Systems, Minneapolis, MN, USA) and mouse TGF- $\beta 1$ (20 ng/ml, PeproTech, Rocky Hill, NJ, USA) were added for Treg polarization. The cells were polarized for 5 days before harvesting.

\section{Flow cytometry}

To analyze the activation and polarization of $\mathrm{CD} 4^{+} \mathrm{T}$ cells, the cells were first cultured for 3 to 5 days with stimulation as mentioned above. In some situations, the cells were restimulated with a cell stimulation cocktail (plus protein transport inhibitors) (Thermo Fisher Scientific, Waltham, MA, USA) for $5 \mathrm{~h}$ before harvesting if intracellular staining for cytokines was needed. For flow staining, the cells were first surface stained with antibodies against CD4, CD69, CD62L, and CD25 conjugated to fluorochromes, and then the cells were fixed and permeabilized with the Foxp3/ Transcription Factor Staining Buffer Set (Thermo Fisher Scientific, Waltham, MA, USA). Then, intracellular staining for Foxp3, IFN- $\gamma$, and IL-17A was performed, followed by fixation using $2 \%$ paraformaldehyde. Isotype plus fluorescence minus one (FMO) controls were used for gating and nonspecific staining exclusion. All antibodies used in this study were purchased from BD Biosciences. Data were acquired on a BD LSRFortessa X-20 or BD Accuri C6 Plus instrument and analyzed with FlowJo software.

\section{Western blot}

Spinal cord tissues were lysed with RIPA lysis buffer (Beyotime, Shanghai, China) containing protease and phosphatase inhibitors (Beyotime, Shanghai, China) and $5 \mathrm{mM}$ EDTA to extract total protein. Protein concentration was measured using a Pierce ${ }^{\mathrm{TM}}$ BCA Protein Assay Kit (Thermo Fisher Scientific, Waltham, MA, USA). Equal amounts of protein $(20 \mu \mathrm{g})$ for each sample were separated by $8 \%$ SDS-PAGE and transferred onto polyvinylidene fluoride (PVDF) membranes. Nonspecific binding was blocked by 5\% BSA for $2 \mathrm{~h}$ at room temperature. The membranes were then incubated with anti-MLK1 (Map3k9) antibody (1:1000, Cat. \#5029, CST, Danvers, MA, USA) and anti- $\beta$-actin antibody (1:2000, Cat. WB0196, Weiao, Shanghai, China) overnight at $4{ }^{\circ} \mathrm{C}$, followed by incubation with HRPconjugated secondary antibodies for $2 \mathrm{~h}$ at room temperature. Blots were visualized using ECL substrate (Weiao, Shanghai, China) on a ChemiDoc ${ }^{\mathrm{TM}}$ imaging system (Bio-Rad, Danvers, MA, USA).

\section{miR-20a knockdown using antagomirs in vivo}

To knock down the expression of miR-20a, chemically modified single-stranded miR-20a antagomirs (purchased from GenePharma Ltd, Shanghai, China) were used. miR-20a antagomirs in the transfection complexes were delivered by tail vein injection to EAE mice. The transfection complexes were prepared with Entranster $^{\mathrm{TM}}$-in vivo (Engreen, Beijing, China) according to the manufacturer's instructions. The miR-20a antagomirs were administered intravenously for 3 days from the day that clinical symptoms appeared (onset stage). For each mouse, $100 \mu \mathrm{g}$ miR-20a antagomirs were injected for the first two days, and $50 \mu \mathrm{g}$ was injected for the third day.

\section{3' UTR luciferase assay}

The wild-type 3' UTR of Map3k9 containing the predicted binding site, mutant 3' UTR, or NC 3' UTR was amplified by PCR and cloned into a luciferase reporter vector (PGL3-CMV-LUC-MCS; Genomeditech, Shanghai, China) by Genomeditech Co., Ltd. Each vector, along with a Renilla luciferase vector (pRL-TK) and miR-20a mimics or control NC mimics, was transfected into HEK293 cells using HG transgene reagent (Genomeditech, Shanghai, China). Cells were harvested and lysed at $48 \mathrm{~h}$ post-transfection. The luciferase activity was measured by an Infinite M1000 plate reader (Tecan, Switzerland), and the results are shown as relative light units (RLUs). The RLU of luciferase reporter containing 3' UTR/RLU of Renilla luciferase ratios were normalized to that of cells cotransfected with luciferase reporter vector containing NC 3' UTR, NC mimics, and pRL-TK. The values of the normalized RLU ratios were used for statistical analysis.

\section{Histological analysis}

The spinal cords harvested from EAE mice were first fixed with $4 \%$ paraformaldehyde, and then the lumbar enlargements were embedded in paraffin and cut into $5-\mu \mathrm{m}$-thick sections, followed by hematoxylin and eosin (H\&E) and Luxol fast blue staining. The number of infiltrating inflammatory cells was counted in the H\&E-stained sections to represent the severity of inflammation, while the demyelination severity is expressed as the percentage of demyelinated area to total white matter area in Luxol fast blue stained sections.

\section{Statistical analysis}

Statistical analysis was carried out using GraphPad Prism software (Version 8.3.1). The Shapiro-Wilk test was used for normality analysis of the data distribution. The unpaired Student's $t$-test or paired Student's $t$-test was used for significant difference analysis between two 
groups. The correlation between the expression of miR20a and Map3k9 was identified with simple linear regression analysis. To compare the severity of disease in the two groups of EAE mice over the entire period of the disease, the area under the curve (RUC) for each mouse was calculated, and the difference was identified with Student's $t$-test. In addition, to compare the severity of disease on each individual day, the clinical scores of the EAE mice from the two groups were analyzed by the MannWhitney test. Data are expressed as the mean \pm SEM, and a $p$-value $<0.05$ was considered significant.

\section{Results}

miR-20a is increased in EAE mice and patients with MOG antibody-associated demyelinating diseases

To determine whether the miR-17-92 cluster is involved in the inflammatory response during EAE progression, we first tested the expression of the 6 miRNAs in the miR-17-92 cluster in splenocytes and lymph node cells. Compared to the control group, the expression levels of miR-17, miR-18a, miR-20a, and miR-92a-1 were increased in EAE mice, while miR-19a and miR19b-1 were expressed equivalently between the two groups (Fig. 1A). We next detected the expression of miR-17, miR-18a, miR-20a, and miR-92a-1 in CD4 $4^{+} \mathrm{T}$ cells isolated from EAE and control mice, and miR-17 and miR-20a were found to be upregulated in EAE mice (Fig. 1B). Furthermore, the same results for miR-17 and miR-20a were also observed in spinal cord tissue of EAE and control mice (Fig. 1C). To determine the importance of the miRNAs in patients, we tested the expression level of the miRNAs in peripheral blood leukocytes from patients with MOG antibody-associated demyelinating diseases. Increased expression levels of miR-17, miR18a, miR-20a, and miR-92a-1 were detected in peripheral blood leukocytes from patients compared with healthy controls (Fig. 1D), which were consistent with the results in splenocytes and lymph node cells from EAE mice. The above findings indicated that miR-17-92 cluster may be involved in inflammatory demyelinating diseases of the CNS. Moreover, miR-17 and miR-20a may play an important role in the development of EAE by affecting $\mathrm{CD} 4^{+}$ $\mathrm{T}$ cells. The function of miR-17 in EAE mice has been previously reported [35], while the function of miR-20a remains unclear. We, therefore, chose miR-20a for further study.

\section{miR-20a does not affect CD4 ${ }^{+} \mathrm{T}$ cell activation in EAE}

We first explored whether miR-20a affects the activation of MOG-specific $\mathrm{CD} 4^{+} \mathrm{T}$ cells in EAE mice. To knock down the expression level of miR-20a, chemically modified antagomirs that are complementary
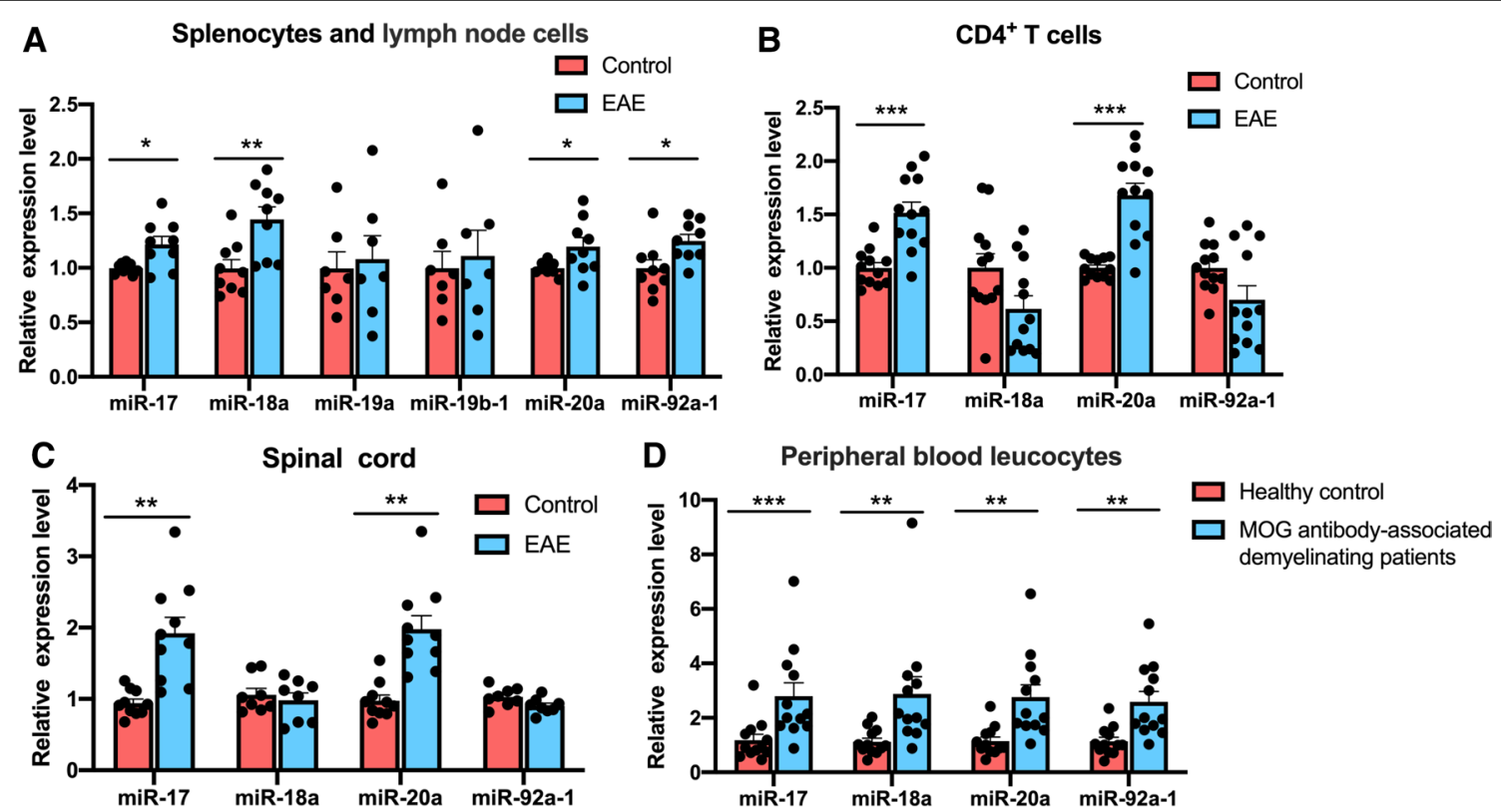

Fig. 1 Different expression levels of miR-17-92 cluster in EAE mice and MOG antibody-associated demyelinating patients. A The expression levels of miR-17-92 cluster members in splenocytes and lymph node cells of EAE and control mice $(n=7-9)$. B The expression levels of miR-17-92 cluster members in isolated peripheral $C D 4^{+} T$ cells of EAE and control mice $(n=12)$. C The expression levels of miR-17-92 cluster members in spinal cord tissues of EAE and control mice $(n=8-10)$. D The expression levels of miR-17, miR-18a, miR-20a, and miR-92a-1 in the peripheral blood leucocytes of MOG antibody-associated demyelinating patients and healthy controls $(H C)(n=12)$. Data are shown as mean \pm SEM. ${ }^{*} p<0.05,{ }^{* *} p<0.01,{ }^{* * *}$ $p<0.001$ using unpaired Student's t-test 
to mature miR-20a were used. The knockdown efficiency of the miR-20a antagomirs is shown in Additional file 2: Figure $\mathrm{S} 1$. Isolated $\mathrm{CD} 4^{+} \mathrm{T}$ cells from the spleens and lymph nodes of EAE mice were transfected with miR-20a or negative control (NC) antagomirs and stimulated with $\mathrm{MOG}_{35-55}$ peptide for 3 days. Every day, activated $\mathrm{CD} 4^{+} \mathrm{T}$ cells defined as $\mathrm{CD} 4{ }^{+} \mathrm{CD} 62 \mathrm{~L}^{\text {low }} \mathrm{CD} 25^{+}$or $\mathrm{CD} 4{ }^{+} \mathrm{CD} 69^{+}$were analyzed by flow cytometry. The results showed that neither the percentage of $\mathrm{CD} 4{ }^{+} \mathrm{CD} 62 \mathrm{~L}^{\text {low }} \mathrm{CD} 25^{+}$(Fig. 2A, B) nor that of $\mathrm{CD} 4{ }^{+} \mathrm{CD} 69^{+} \mathrm{T}$ cells (Fig. 2C, D) was significantly different between the NC and miR-20a antagomir groups. The data indicated that miR-20a does not affect the activation of MOG-specific $\mathrm{CD}^{+} \mathrm{T}$ cells in EAE.

\section{miR-20a suppresses Treg differentiation in EAE}

Since miR-20a does not affect the activation of $\mathrm{CD} 4^{+}$ $\mathrm{T}$ cells in $\mathrm{EAE}$, we next hypothesized that miR-20a is involved in the differentiation of $\mathrm{CD}_{4}{ }^{+} \mathrm{T}$ cells. Th1 and Th17 cells are crucial effector cells in EAE initiation and progression [36], while Treg cells suppress excessive autoimmune responses [37]. We first examined the mRNA levels of characteristic cytokines and transcription factors of Treg, Th1, and Th17 cells in $\mathrm{CD}_{4}^{+} \mathrm{T}$ cells of EAE and control mice. The mRNA expression of
A
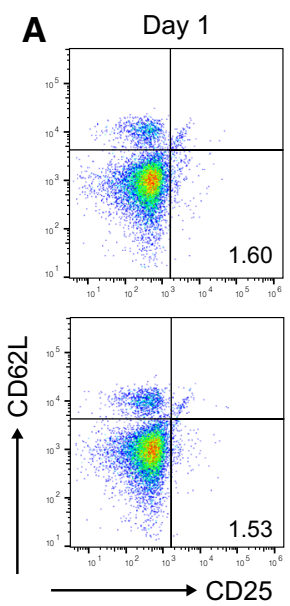
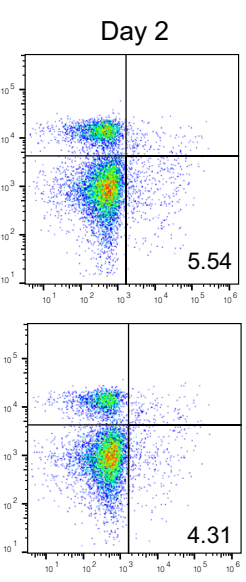

CD4 Gated
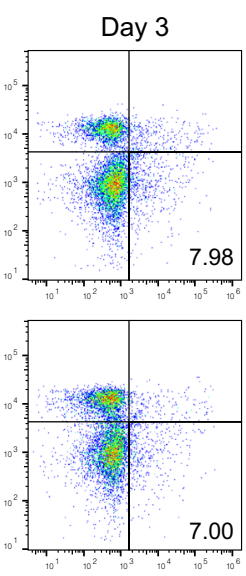

miR-20a antagomir
B

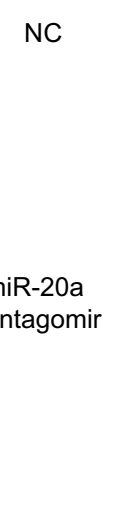

D
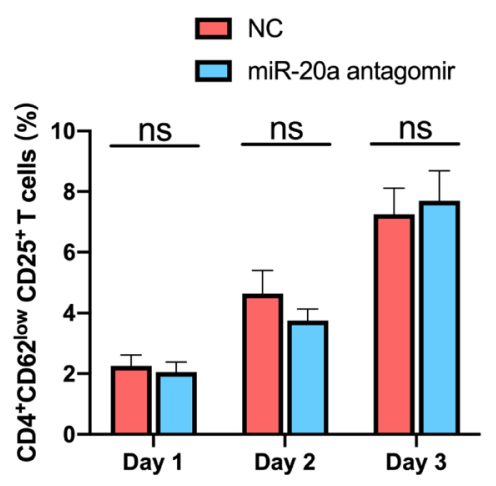

C
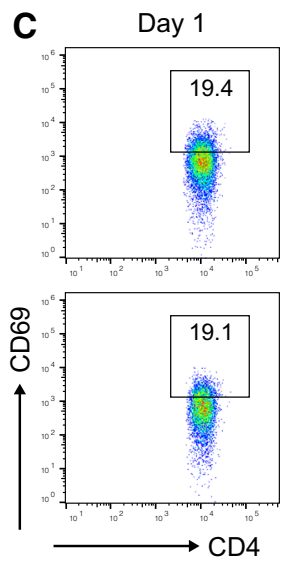

Day 2
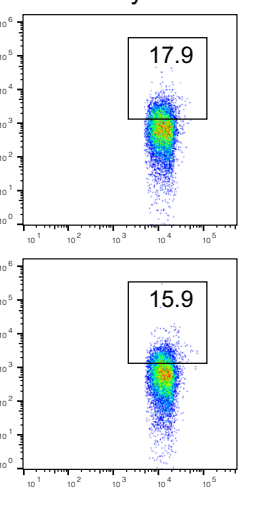

CD4 Gated
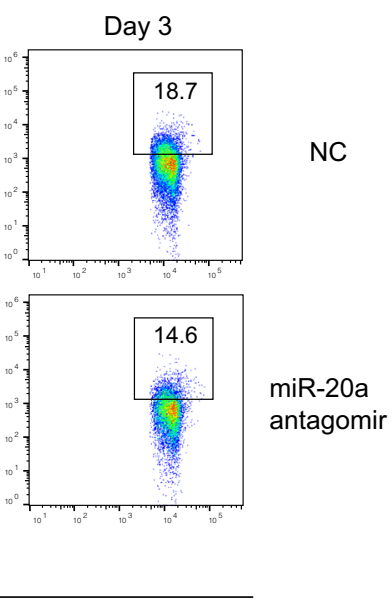
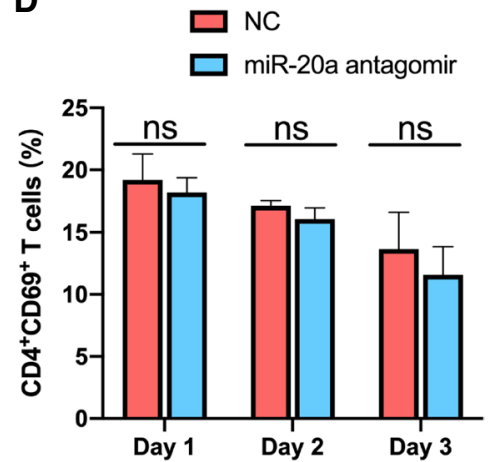

Fig. 2 miR-20a does not affect the activation of MOG-specific CD4 ${ }^{+}$T cells in EAE mice. A, B The percentages of CD62 $L^{\text {low }} C D 25^{+}$cells in the CD4 ${ }^{+}$ gate, as measured by flow cytometry on Day 1, Day 2 and Day 3, separately. C, D The percentages of CD69+ cells in the CD4 $4^{+}$gate, as measured by flow cytometry on Day 1, Day 2 and Day 3, separately. The flow cytometry plots shown are representative of 3 independent experiments. Data are presented as mean \pm SEM and ns represents no significant difference 
Foxp3 was reduced in EAE mice compared to the control group (Fig. 3A). Similarly, IL-10, the major anti-inflammatory cytokine secreted by Tregs, was also downregulated in EAE mice, though the expression of TGF- $\beta 1$, another cytokine produced by Tregs, was comparable between the two groups (Fig. 3B). It should be noted that although IFN- $\gamma$ and IL-17A were upregulated in EAE mice, the mRNA expression levels of T-bet (Tbx21) and RORyt (Rorc) were equivalent across the two groups (Fig. 3A, B). Thus, we speculated that miR-20a may affect the differentiation of Treg cells. Naïve $\mathrm{CD}^{+}{ }^{+} \mathrm{T}$ cells $\left(\mathrm{CD} 4^{+} \mathrm{CD} 25^{-} \mathrm{CD} 44^{-}\right)$isolated from naïve mice were Treg-polarized in vitro for 4 days, and we found that the mRNA levels of both Foxp3 (Fig. 3C) and IL-10 (Fig. 3D) significantly increased in $\mathrm{CD} 4^{+} \mathrm{T}$ cells with miR-20a knockdown. We next polarized $\mathrm{CD}^{+} \mathrm{T}$ cells from EAE mice into Tregs with IL- 2 and TGF- $\beta 1$ under the $\mathrm{MOG}_{35-55}$ stimulation. It was found that IL- 2 and TGF- $\beta 1$ successfully induced the differentiation of MOG-specific $\mathrm{CD}^{+} \mathrm{T}$ cells into Tregs under the $\mathrm{MOG}_{35-55}$ stimulation (Fig. 3E, F). Furthermore, the Treg differentiation was enhanced in the miR-20a knockdown group compared to the NC group. (Fig. 3E, F). The results collectively indicated that miR-20a suppresses the differentiation of Treg cells while reducing the expression level of miR-20a promotes Treg differentiation.

\section{Map3k9 is a potential target gene of miR-20a}

We next investigated the mechanism by which miR-20a regulates the differentiation of Treg cells. We identified potential downstream gene targets of miR-20a using three online prediction tools based on the binding sites in the 3' UTR, including TargetScan (www.targetscan. org), microT-CDS (http://www.microrna.gr/webServer) and miRDB (www.mirdb.org) (Fig. 4A). Among all of the putative gene targets, 532 overlapping targets of the three programs were functional enrichment analyzed on GO and KEGG pathway databases by the WebGestalt online tool (http://www.webgestalt.org) (Fig. 4B, C). We selected some potential gene targets that are functionally involved in inflammatory responses and tested their mRNA levels in splenocytes and lymph node cells of EAE and control mice. The expression of Map3k9 (mitogen-activated protein kinase kinase kinase 9) was downregulated in EAE
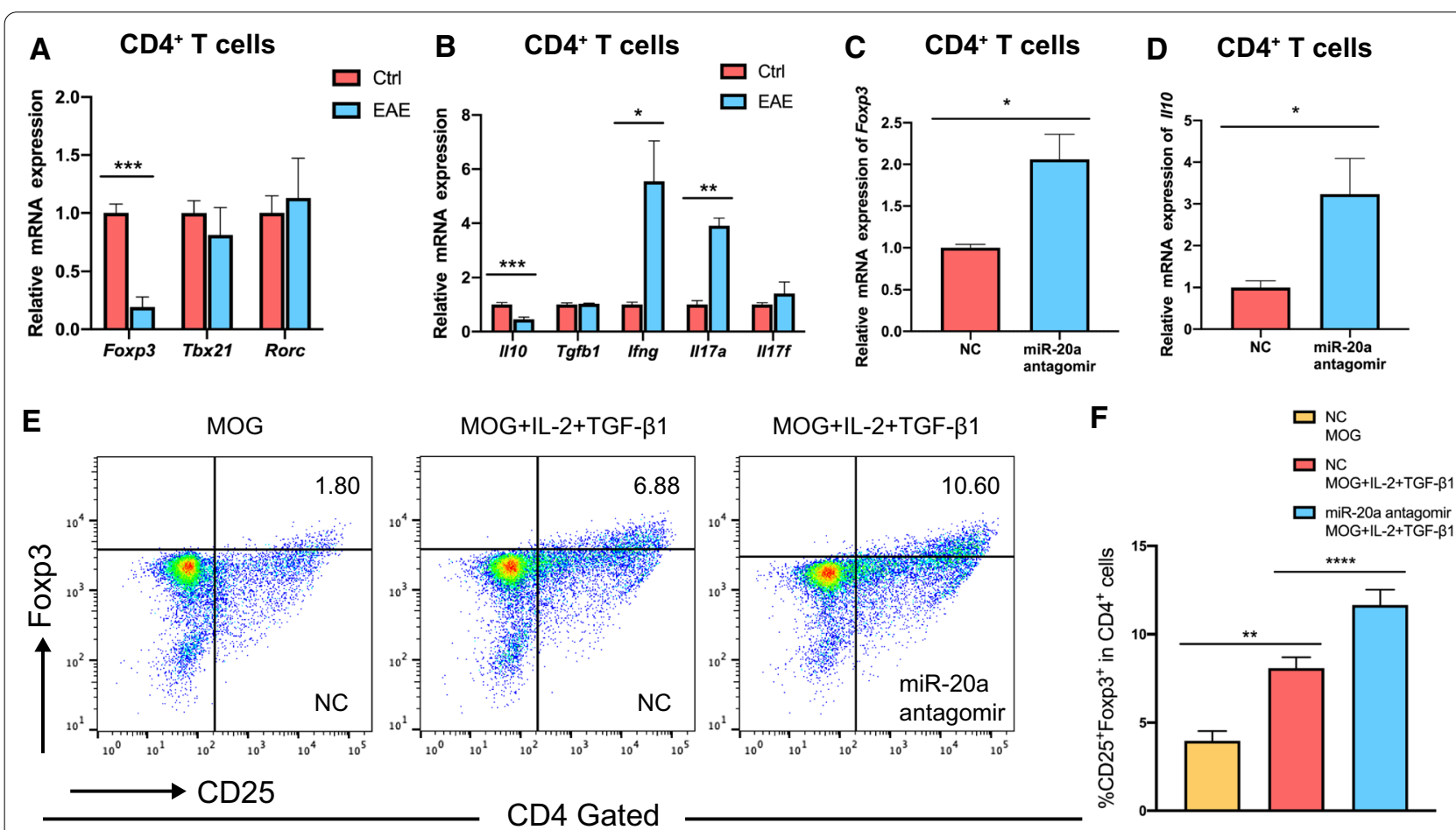

Fig. 3 miR-20a suppresses Treg differentiation in EAE. A The mRNA levels of characteristic transcription factors of Treg (Foxp3), Th1 (Tbx21) and Th17 (Rorc) cells in CD4 ${ }^{+}$T cells of EAE and control mice. B The mRNA levels of characteristic cytokines of Treg (II-10, Tgfb1), Th1 (Ifng) and Th17 $(I-17 a, \|-17 f)$ cells in $\mathrm{CD}^{+} \mathrm{T}$ cells of EAE and control mice. C The mRNA levels of Foxp3 in Treg-polarized CD4 ${ }^{+} \mathrm{T}$ cells with miR-20a or NC antagomirs transfected. D The mRNA levels of II-10 in Treg-polarized CD4 ${ }^{+} \mathrm{T}$ cells with miR-20a or NC antagomirs transfected. $\mathbf{E}$, $\mathbf{F}$. The percentages of $\mathrm{CD}_{25}{ }^{+} \mathrm{Foxp}^{+}$cells in $\mathrm{CD}^{+} \mathrm{T}$ cells of EAE mice after a 5-day MOG $35-55$ stimulation and Treg polarization with miR-20a or NC antagomirs transfected. The flow cytometry plots shown are representative of 6 independent experiments. Data are shown as mean \pm SEM. ${ }^{*} p<0.05$, ${ }^{* *} p<0.01,{ }^{* * * *}$ $p<0.0001$ using unpaired $(\mathbf{A}-\mathbf{D})$ and paired $(\mathbf{F})$ Student's $t$-test 


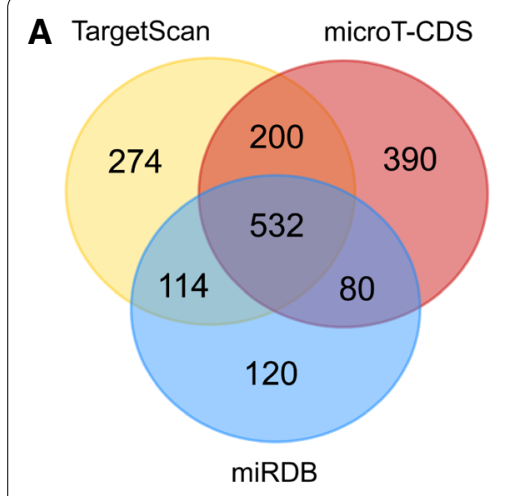

B

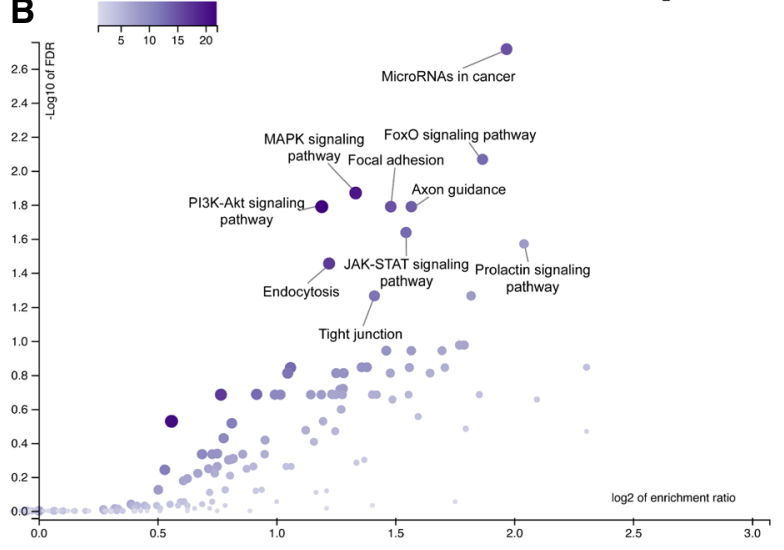

Fig. 4 Prediction and initial validation of the target genes of miR-20a. A The potential target genes of miR-20a predicted by TargetScan, microT-CDS, and miRDB. 532 overlapping targets predicted by the three online programs were then functional enrichment analyzed. B a GO slim summary for the 532 target genes annotated by the online WebGestalt tool. C Functional annotation of the 532 overlapping genes based on KEGG pathway Database by the online WebGestalt tool. D The mRNA expression levels of 7 selected potential target genes in EAE and control mice $(n=6-9)$. Data are shown as mean \pm SEM. ${ }^{*} p<0.05,{ }^{* *} p<0.001$ using unpaired Student's $t$-test mice (Fig. 4D), which makes Map3k9 a potential gene target of miR-20a. Tgfbr2 (transforming growth factor beta receptor 2) was also downregulated in EAE mice; however, we next found that Tgfbr2 was upregulated in $\mathrm{CD}^{+} \mathrm{T}$ cells of EAE mice, which refuted the speculation that Tgfbr2 was a miR-20a target gene (data not shown).

\section{Expression of Map3k9 is influenced by miR-20a}

Since Map3k9 was downregulated in EAE mice when miR-20a was upregulated, we next investigated the correlation between the expression of Map3k9 and miR-20a. The mRNA level of Map3k9 was decreased in $\mathrm{CD}^{+}{ }^{+} \mathrm{T}$ cells in EAE mice (Fig. 5A). Furthermore, the mRNA and protein levels of Map3k9 were also decreased in the spinal cords of EAE mice (Fig. 5B-D). In addition, by linear regression analysis, a significant negative correlation between the mRNA levels of miR-20a and Map3k9 was shown in both $\mathrm{CD}^{+} \mathrm{T}$ cells and spinal cord tissues from EAE and control mice (Fig. 5E, F). We finally validated this result in patients and found that the mRNA level of
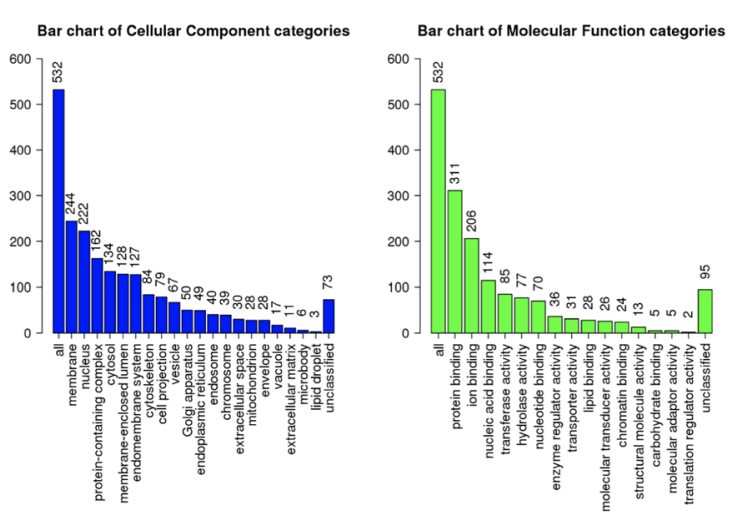

\section{Splenocytes and lymph node cells}
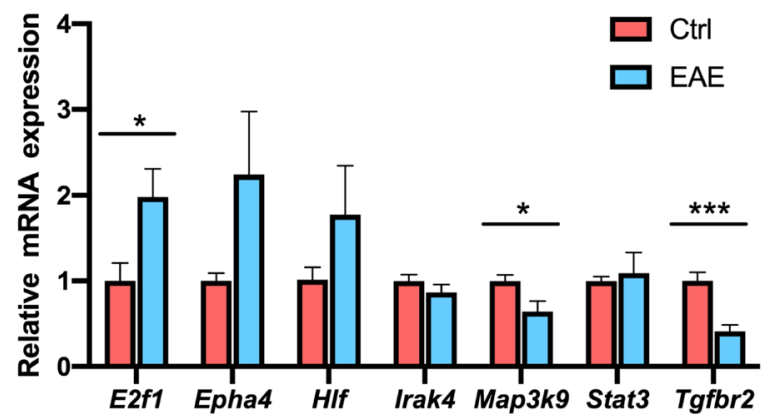

Map3k9 was decreased in peripheral blood leukocytes from patients with MOG antibody-associated demyelinating disease compared to healthy controls (Fig. 5G). Taken together, these results indicate that the expression of Map3k9 is influenced by that of miR-20a.

\section{Map3k9 is a target gene of miR-20a to suppress Treg differentiation in EAE}

To determine whether Map3k9 is the target gene for miR-20a to suppress Treg differentiation in EAE, we first knocked down the expression of miR-20a in CD4 ${ }^{+}$ $\mathrm{T}$ cells and observed a significantly increased expression of Map3k9 (Fig. 6A). According to the results of target gene prediction, a putative binding site for miR20a in the 3' untranslated region (UTR) of Map3k9 was identified. We next performed luciferase reporter assays to detect the binding of miR-20a and the 3' UTR of Map3k9 (Fig. 6B). The results showed that miR-20a specifically suppressed the luciferase activity of the reporter containing the wild-type 3' UTR of Map3k9 


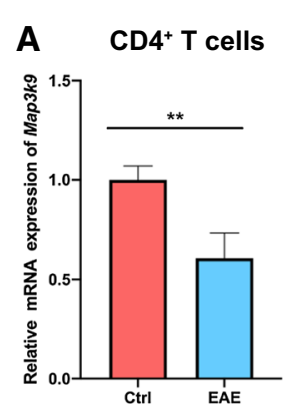

E $\quad$ CD4 $^{+} \mathrm{T}$ cells

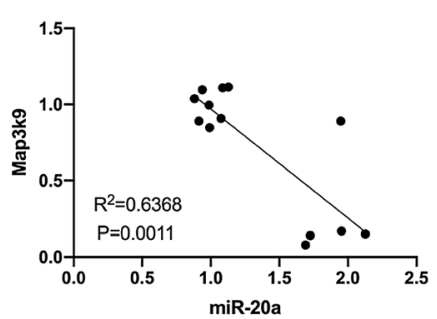

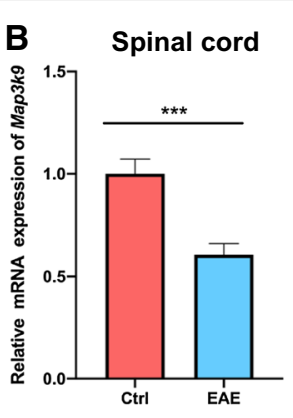

$\mathbf{F}$

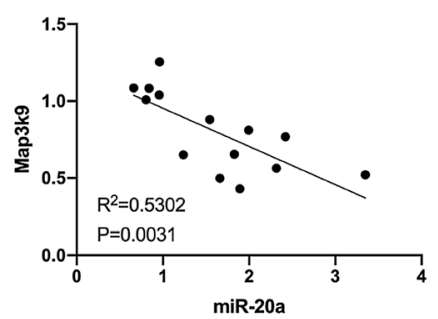

D

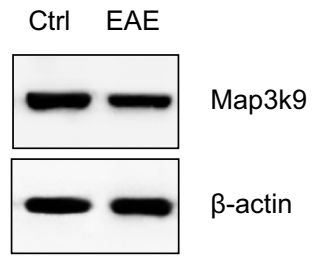

G Peripheral blood leucocytes

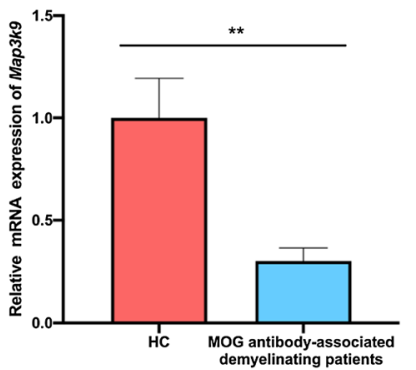

Fig. 5 The expression of Map3k9 is influenced by miR-20a. A The mRNA expression level of Map3k9 in CD4 ${ }^{+}$T cells from EAE and control mice. B The mRNA expression level of Map3k9 in spinal cord tissues from EAE and control mice. C, D. The protein expression level of Map3k9 in spinal cord tissues from EAE and control mice tested by western blot. $\mathbf{E}$ Linear regression analysis of the correlation between the expression of miR-20a and Map3k9 in CD4 ${ }^{+} \mathrm{T}$ cells from EAE and control mice. $\mathbf{F}$ Linear regression analysis of the correlation between the expression of miR-20a and Map3k9 in spinal cord tissues from EAE and control mice. G The mRNA level of Map3k9 in the peripheral blood leucocytes of MOG antibody-associated demyelinating patients and HCs. Data are shown as mean \pm SEM. ${ }^{* *} p<0.01,{ }^{* * *} p<0.001$ using unpaired Student's t-test

while the reporter containing a mutant or NC 3' UTR was not affected, indicating effective and specific binding of miR-20a to the predicted binding site in Map3k9 (Fig. 6C). At this point, we have demonstrated that Map3k9 is a target gene of miR-20a.

We finally explored whether miR-20a inhibits the differentiation of Tregs in EAE mice by reducing the expression of Map3k9. To this end, isolated $\mathrm{CD} 4^{+} \mathrm{T}$ cells were transfected with antagomirs or were cotransfected with miR-20a antagomirs and Map3k9 siRNA (The knockdown efficiency of the siRNA is shown in Additional file 3: Figure S2). The cells were polarized into Tregs under $\mathrm{MOG}_{35-55}$ stimulation as mentioned above. The results showed that $\mathrm{CD} 4^{+} \mathrm{T}$ cells transfected with the miR-20a antagomirs alone displayed an enhanced capacity to differentiate into Treg cells, which was consistent with the previous results (Fig. 6D, E). However, the results did not show any difference in Treg differentiation between the $\mathrm{CD} 4^{+} \mathrm{T}$ cells transfected with miR-20a antagomirs + Map3k9 siRNA and the $\mathrm{NC}$ antagomirs (Fig. 6D, E). The findings suggested that miR-20a suppresses differentiation of MOG-specific $\mathrm{CD}^{+}{ }^{+} \mathrm{T}$ cells into Tregs in EAE mice by reducing the expression of Map3k9.
Collectively, our results suggest that Map3k9 is a functional target of miR-20a to suppress Treg differentiation in EAE.

miR-20a antagomir treatment alleviates the severity of EAE in vivo

As described above, we demonstrated that miR-20a suppresses Treg differentiation of MOG-specific CD4 $4^{+}$ $\mathrm{T}$ cells in EAE mice. We next explored whether miR20a knockdown in EAE mice could alleviate the severity of EAE in vivo. We injected EAE mice intravenously with miR-20a or the NC antagomirs for 3 consecutive days at the onset of the disease and observed the clinical scores until the remission stage. The highest clinical score for mice injected with miR-20a antagomirs was 2.5 compared to 3.5 in mice injected with the NC antagomirs. In addition, as shown in Fig. 7, the average area under the scoring curve of the miR-20a antagomir group throughout the observation period was smaller than that of the NC group. For the individual days, the scores for the miR-20a antagomir group on Day 18 and Day 19 postimmunization were lower than those for the NC group. All of the above results indicated that 

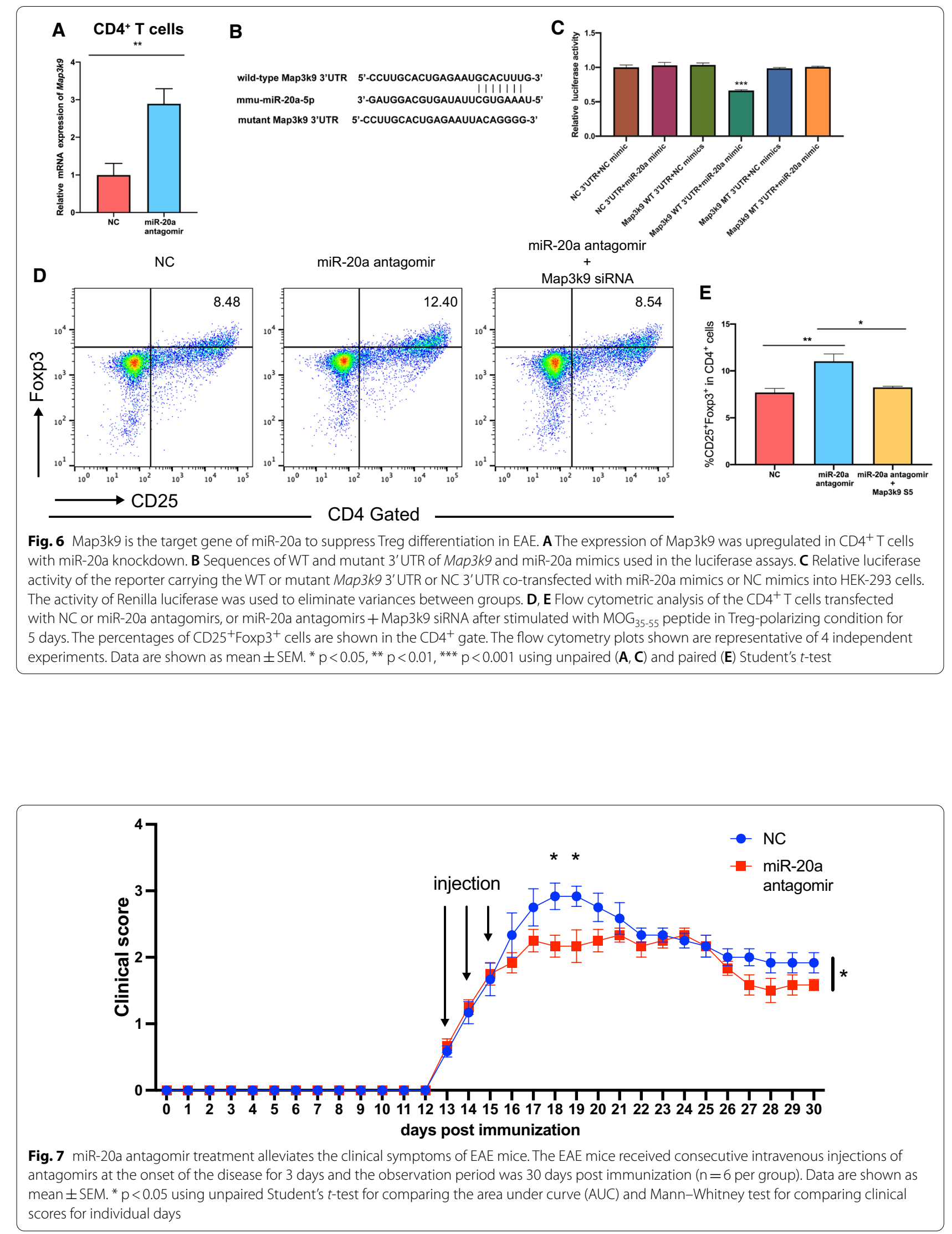
miR-20a knockdown with antagomirs attenuates the clinical symptoms of EAE.

We also performed the pathological analysis of spinal cord sections from EAE mice by hematoxylin and eosin (H\&E) staining and Luxol fast blue staining. The amount of infiltrating inflammatory cells in the miR20a antagomir group was less than that in the NC group (Fig. 8A-E). In addition, the percentage of demyelinated area to total white matter area (demyelinated area \%) was lower in the miR-20a antagomir group than that in the NC group (Fig. 9A-E). Furthermore, by analyzing the $\mathrm{CD} 4^{+} \mathrm{T}$ cells from the two groups at the remission stage of the disease with flow cytometry, we observed that the percentages of IFN $-\gamma^{+}$Th 1 cells and IL-17A ${ }^{+}$ Th17 cells in the $\mathrm{CD} 4^{+}$gate were similar between the miR-20a antagomir and NC groups (Fig. 10A-C), while the percentage of $\mathrm{CD} 25^{+}$Foxp $3^{+}$Treg cells in the miR20a antagomir group was higher than that in the NC group (Fig. 10D, E). Collectively, the results showed that miR-20a knockdown with antagomirs alleviates the clinical symptoms of EAE, decreases inflammatory infiltration, reduces myelin damage, and promotes the differentiation of Treg cells in EAE mice. These findings suggest a potential therapeutic role of miR-20a antagomirs in the treatment of EAE and CNS inflammatory demyelinating diseases.

\section{Discussion}

The miR-17-92 cluster was first identified because of its oncogenic effects in a variety of tumors, such as leukemia, lymphoma, and cancers derived from the colon, breast, ovary, and pancreas [22, 24]. In recent years, an increasing number of studies have shown the involvement of miR-17-92 in autoimmune diseases. It is found that miR-17-92 is a critical regulator of follicular helper $\mathrm{T}$ (Tfh) cells differentiation in an ovalbumin (OVA)induced model of autoimmunity [38]. miR-17-92 also plays an essential role in the activation, proliferation, survival, and differentiation of $\mathrm{CD}_{4}^{+} \mathrm{T}$ cells in graftversus-host disease (GVHD) [27, 28]. In addition, members of the miR-17-92 cluster were upregulated in CD4 ${ }^{+}$ $\mathrm{T}$ cells from patients with systemic lupus erythematosus (SLE) [39], and miR-17 affects TNF- $\alpha$ signaling in rheumatoid arthritis [40]. Members of the miR-17-92 cluster are also dysregulated in CNS inflammatory demyelinating diseases, and some of them are restored to normal levels after medical treatment or during remission [30, 32-34, 41-44]. The findings in some studies are contradictory, which may be attributed to the different clinical stages of the patients; however, miR-17-92 cluster is still recognized as an important regulator of CNS inflammatory demyelinating diseases. Nevertheless, the role and mechanism of miR-17-92 cluster in CNS inflammatory
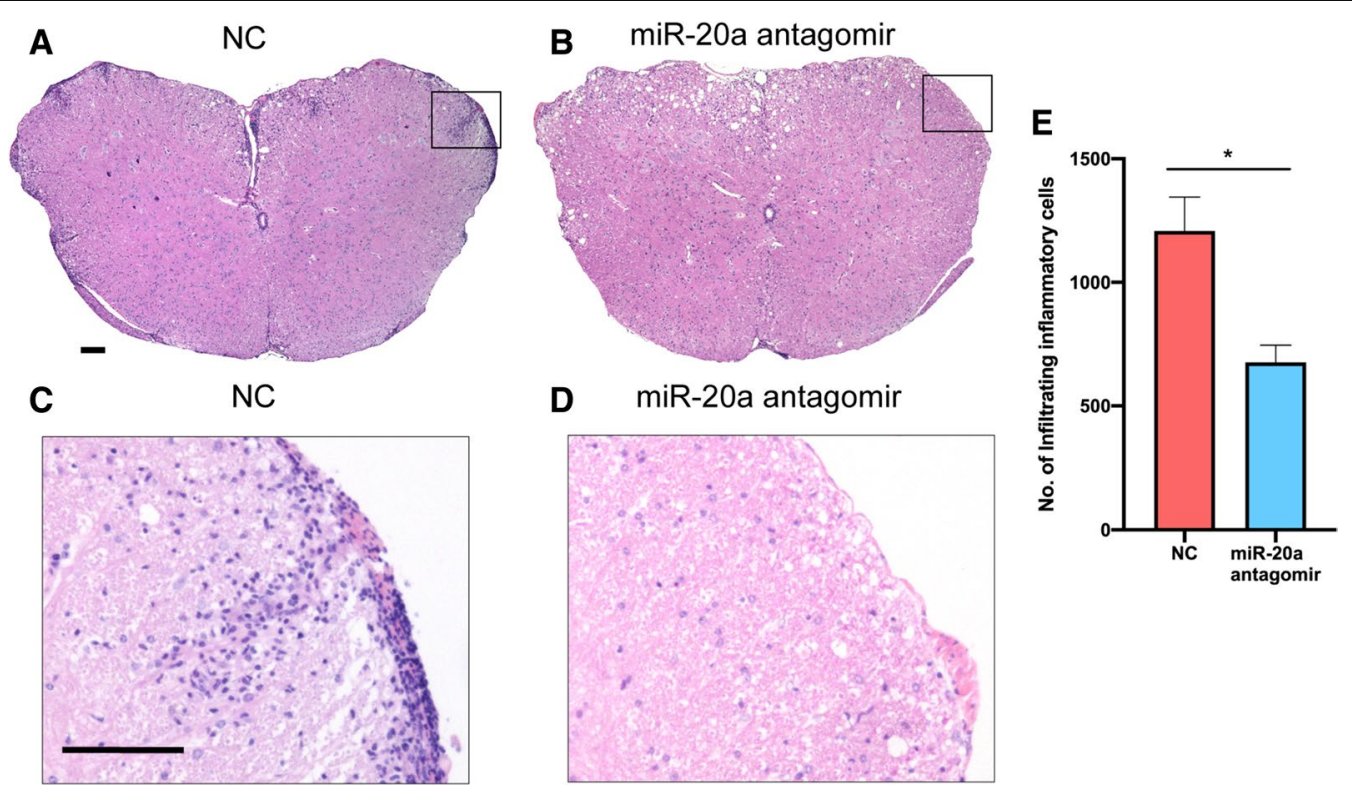

Fig. 8 miR-20a antagomir treatment reduces the infiltrating inflammatory cells in spinal cords of EAE mice. A Representative H\&E staining of complete spinal cord sections from NC group (taken at $\times 10$ magnification). B Representative H\&E staining of complete spinal cord sections from miR-20a antagomir group (taken at $\times 10$ magnification). C Representative H\&E staining of partial spinal cord sections from NC group (taken at $\times 20$ magnification). D Representative H\&E staining of partial spinal cord sections from miR-20a antagomir group (taken at $\times 20$ magnification). E Quantification of the infiltrating inflammatory cells in the two groups. Scale bars correspond to $100 \mu \mathrm{m}$. Data are shown as mean \pm SEM. ${ }^{*} p<0.05$ using unpaired Student's $t$-test 


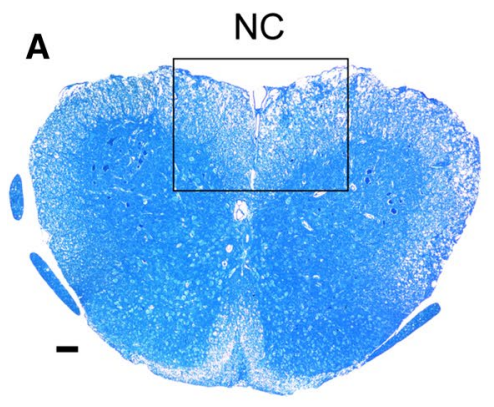

C

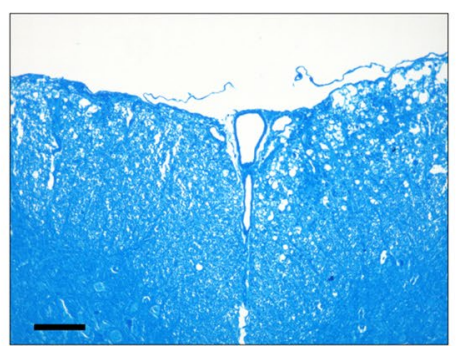

B miR-20a antagomir

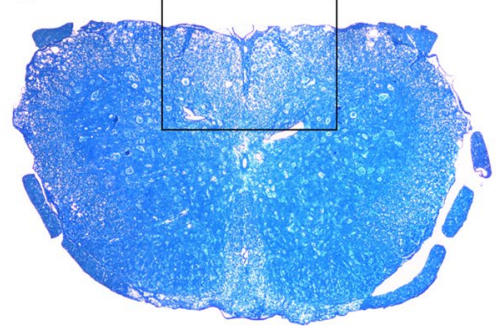

D miR-20a antagomir

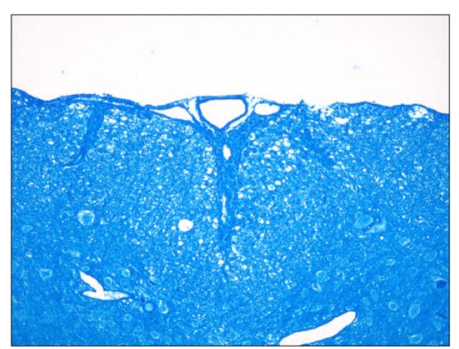

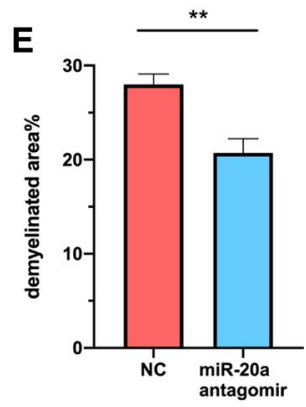

Fig. 9 miR-20a antagomir treatment decreases demyelinated areas in spinal cords of EAE mice. A Representative Luxol fast blue staining of complete spinal cord sections from NC group (taken at $\times 10$ magnification). B Representative Luxol fast blue staining of complete spinal cord sections from miR-20a antagomir group (taken at $\times 10$ magnification). C Representative Luxol fast blue staining of partial spinal cord sections from NC group (taken at $\times 20$ magnification). D Representative Luxol fast blue staining of partial spinal cord sections from miR-20a antagomir group (taken at $\times 20$ magnification). $\mathbf{E}$ Quantification of the percentage of demyelinated area to total white matter area in the two groups. Scale bars correspond to $100 \mu \mathrm{m}$. The demyelinated areas and total white matter areas were calculated with ImageJ software. Data are shown as mean \pm SEM. ** $p<0.01$ using unpaired Student's $t$-test
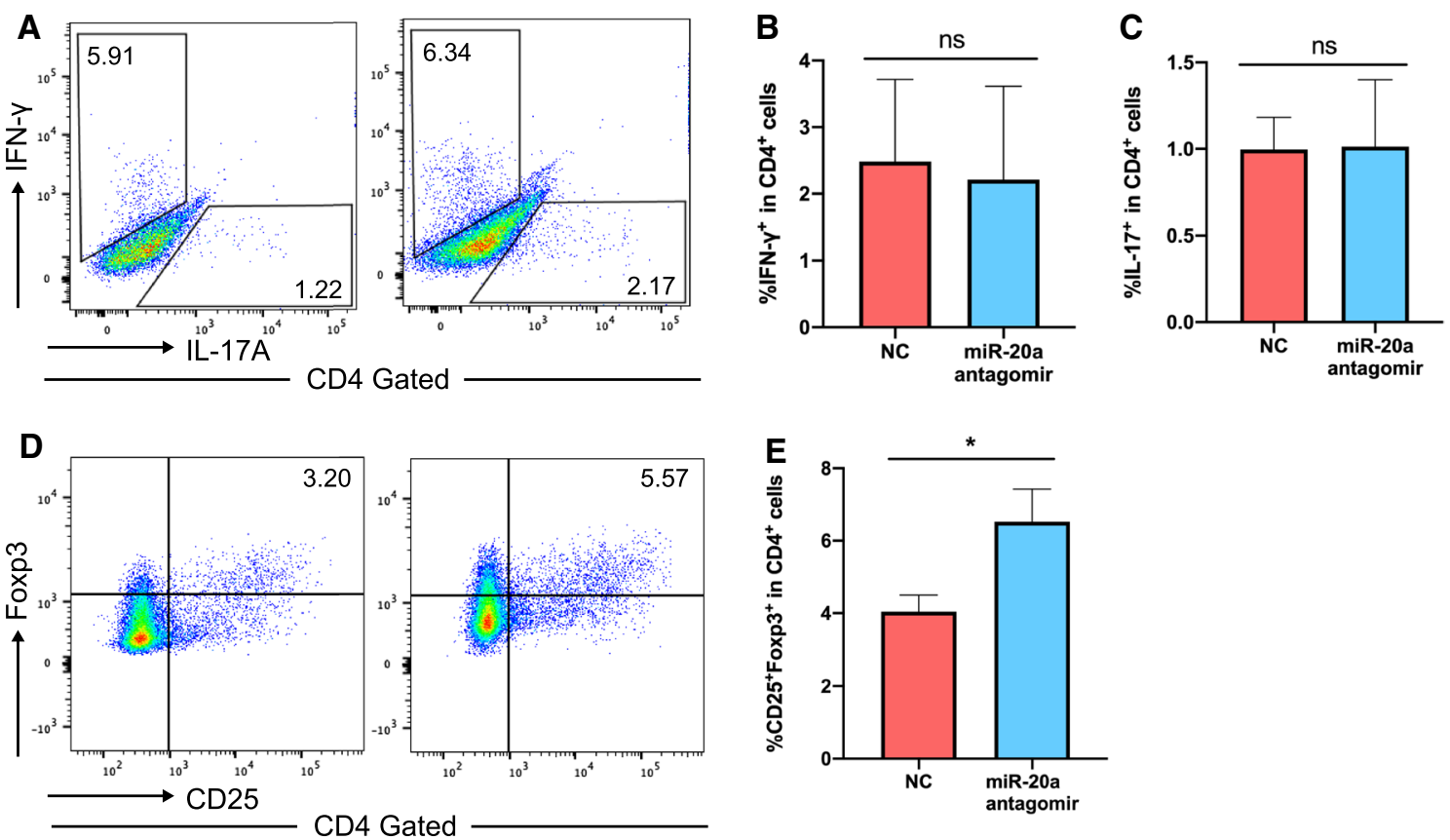

Fig. 10 miR-20a antagomir treatment promotes Treg differentiation in EAE mice. A-C Flow cytometric analysis of IFN- $\gamma^{+}$and IL-17A ${ }^{+}$cells in CD4 ${ }^{+}$ T cells of miR-20a antagomir and control group. D, E Flow cytometric analysis of CD25 $5^{+} \mathrm{Fxp}^{+}$cells in $\mathrm{CD} 4^{+} \mathrm{T}$ cells of miR-20a antagomir and control group. The flow cytometry plots shown are representative of 4 independent experiments. Data are shown as mean \pm SEM. ${ }^{*} p<0.05$ using unpaired Student's t-test 
demyelinating diseases are still unclear and remain to be further explored.

In this study, we observed the upregulation of miR-20a in splenocytes and lymph node cells from EAE mice and peripheral blood leukocytes from patients with MOG antibody-associated demyelinating diseases and further found that miR-20a was upregulated in $\mathrm{CD}^{+} \mathrm{T}$ cells and spinal cord tissues from EAE mice. EAE is mediated mainly by $\mathrm{CD} 4^{+} \mathrm{T}$ cells in which $\mathrm{Th} 1$ and Th17 cells are major pathogenic cells while Treg cells play an important role in suppressing inflammatory responses. We speculated that miR-20a may involve in the development of EAE by targeting $\mathrm{CD} 4^{+} \mathrm{T}$ cells. In our study, no evidence showed that miR-20a affects the activation of MOG-specific $\mathrm{CD} 4^{+} \mathrm{T}$ cells, we then found for the first time that miR-20a knockdown promotes the differentiation of MOG-specific $\mathrm{CD}^{+}{ }^{+} \mathrm{T}$ cells into Tregs, revealing the role of miR-20a in suppressing Treg differentiation in EAE. Jin et al. found that protectin DX increases the proportion of Tregs in a collagen-induced arthritis model by inhibiting NLRP3 inflammasome via miR-20a [45], which appears to be contrary to the findings in our study. However, the animal models used in these two studies are quite different and the important influencing factor in Jin's study, protectin DX treatment, was not involved in our study, which makes contrasting results in the two studies possible.

In addition, in this study, we observed that miR-20a knockdown using antagomirs in EAE mice in vivo did not affect the proportion of IFN- $\gamma^{+}$Th1 and IL-17A ${ }^{+}$ Th17 cells. However, Chang et al. found that miR-20a reduces the proportion of $\mathrm{IL}_{-1}-17^{+}$cells in $\mathrm{CD} 4^{+} \mathrm{T}$ cells of patients with Vogt-Koyanagi-Harada disease by targeting OSM and CCL1 [46]. We speculate that the differences between their findings and ours are due to the following reasons. First, the diseases investigated in the two studies are different, which leads to completely different pathological states of the $\mathrm{CD}^{+}{ }^{+} \mathrm{T}$ cells. Second, the results in Chang's study were obtained through in vitro experiments, whereas our findings were obtained through in vivo experiments, which causes the different results in the two studies.

We further investigated the target gene of miR-20a and demonstrated that Map3k9 is a functional target gene of miR-20a to suppress Treg differentiation in EAE through luciferase assays and functional validation. Map3k9, also known as mixed-lineage kinase 1 (MLK1), is an important upstream component in the MAPK pathway as a mitogen-activated protein kinase kinase kinase to activate the c-Jun amino-terminal kinase (JNK), p38, and extracellular-signal regulated kinase (ERK) pathways [47-49]. The MAPK signaling pathway plays an important role in a variety of cellular processes, including proliferation, differentiation, survival, apoptosis, and immune response [50]. In previous studies, downstream components of the MAPK signaling pathway have been found to influence multiple activities of Tregs. Bao et al. demonstrated that JNK increases the levels of Foxp3 protein in $\mathrm{CD} 4{ }^{+} \mathrm{CD} 25^{+}$Treg cells by binding to its promoters [51]. Lu et al. found that bone morphogenetic protein (BMP)-2/4 promotes the differentiation of Tregs induced by TGF- $\beta$ through phosphorylated ERK and JNK [52]. In addition, another study showed that inhibiting the activation of p38 abrogates the proliferation and Foxp3 expression in Tregs induced by tumor necrosis factor (TNF) [53]. Furthermore, it has been revealed that the regulatory function of iTregs is associated with enhanced p38 activity [54]. In this study, we found for the first time that an upstream component of the MAPK signaling pathway, Map3k9, enhances the differentiation of Tregs as a direct target of a miRNA, which further extends the findings on the MAPK signaling pathway.

There are still some limitations in this study. First, the optimal dose, timing, and delivery mode of administration of miR-20a antagomirs to treat EAE mice were not investigated in detail. Considering that miR-20a antagomirs are expected to be a treatment for EAE in the future, the issues described above require more intensive exploration. Second, although the results of patients with MOG antibody-associated demyelinating diseases were consistent with those of EAE mice, it is still inconclusive whether the EAE model perfectly simulates MOG antibody-associated demyelinating diseases. In the following studies, we need to isolate $\mathrm{CD} 4^{+} \mathrm{T}$ cells from patients to validate the results of EAE mice. In addition, we did not validate the results of EAE mice in MS patients, which is another limitation. We will validate the results above in MS patients and compare the results of EAE mice, MS patients, and MOG antibody-associated demyelinating diseases patients in the later studies.

In this study, we found for the first time that miR-20a suppresses the Treg differentiation of MOG-specific $\mathrm{CD}^{+} \mathrm{T}$ cells in EAE by reducing the expression of Map3k9. In addition, our findings indicate the potential role of miR-20a antagomirs in therapies for EAE and CNS inflammatory demyelinating disease. Since the therapeutic effects of a growing number of miRNAs have been verified in clinical trials [55], we expect miR-20a to play a role in the clinical therapies of CNS inflammatory demyelinating diseases in the future.

\section{Conclusions}

In this study, we demonstrated that miR-20a suppresses the differentiation of MOG-specific $\mathrm{CD}^{+}{ }^{+} \mathrm{T}$ cells into Tregs in EAE mice by decreasing the expression of Map3k9. Administration of miR-20a antagomirs to EAE 
mice reduces the severity of the disease, suggesting a potential role of miR-20a in therapies for EAE and CNS inflammatory demyelinating diseases.

\section{Abbreviations}

CNS: Central nervous system; EAE: Experimental autoimmune encephalomyelitis; UTR: Untranslated region; MS: Multiple sclerosis; NMOSD: Neuromyelitis optica spectrum disorder; MOG: Myelin oligodendrocyte glycoprotein; Th: T helper; Treg: Regulatory T cell; iTreg: Induced regulatory T cell; Tfh: FollicuIar helper T cell; IFN-ү: Interferon-ү; WT: Wild-type; IL: Interleukin; GM-CSF: Granulocyte-macrophage colony-stimulating factor; TGF- $\beta 1$ :Transforming growth factor- $\beta 1$; Foxp3: Forkhead box P3; RORyt: RAR-related orphan receptor gamma-t; GO: Gene Ontology; KEGG: Kyoto Encyclopedia of Genes and Genomes; Map3k9: Mitogen-activated protein kinase kinase kinase 9; Tgfbr2: Transforming growth factor beta receptor 2; CFA: Complete Freund's adjuvant; PTX: Pertussis toxin; MACS: Magnetic bead cell sorting; siRNA: Small interfering RNA; NC: Negative control; HEPES: N-2-Hydroxyethylpiperazine-N-2-Ethane Sulfonic Acid; RIPA: Radioimmunoprecipitation assay; EDTA: Ethylenediamine tetraacetic acid; SDS: Sodium dodecyl sulfate; PAGE: Polyacrylamide gel; PVDF: Polyvinylidene fluoride; BSA: Bovine serum albumin; H\&E: Hematoxylin and eosin; OVA: Ovalbumin; GVHD: Graft-versus-host disease; SLE: Systemic lupus erythematosus; MLK1: Mixed-lineage kinase 1; JNK: C-Jun amino-terminal kinase; ERK: Extracellular-signal regulated kinase; TNF: Tumor necrosis factor; BMP: Bone morphogenetic protein.
\end{abstract}

\section{Supplementary Information}

The online version contains supplementary material available at https://doi. org/10.1186/s12967-021-02893-4.

Additional file 1: Table S1. The primers used in the study.

Additional file 2: Figure S1. The knockdown efficiency of the miR-20a antagomirs.

Additional file 3: Figure S2. The knockdown efficiency of the Map3k9 SiRNA.

\section{Acknowledgements}

We give our sincere gratitude to the patients who participated in this study and the reviewers for their valuable suggestions.

\section{Authors' contributions}

YW designed the experiments, performed the cellular experiments and drafted the manuscript; CX and YS coordinated the study and edited the manuscript; WX and JP performed the animal experiments; LH and JD provided technical support; YG conceived the study, edited the manuscript, and administered the project. All authors read and approved the final manuscript.

\section{Funding}

This research was supported by grants from the National Natural Science Foundation of China (81771295, 82071341, 81801195), the Special Construction Fund for Integrating Chinese and Western Medicine in General Hospitals (ZHYY-ZXJHZX-1-201701), and Innovative research team of high-level local universities in Shanghai and Shanghai Sailing program (18YF1413100).

\section{Availability of data and materials}

All data are available in the manuscript or upon request to the authors.

\section{Declarations}

Ethics approval and consent to participate

All animal experiments were approved by the Animal Ethics and Welfare Committee of Renji Hospital affiliated to Shanghai Jiao Tong University School of Medicine. All experiments involving human blood samples were approved by the Ethics Committee of the Renji Hospital affiliated to Shanghai Jiao Tong University School of Medicine.
Consent for publication

Not applicable.

\section{Competing interests}

The authors declare that they have no competing interests.

Received: 13 April 2021 Accepted: 17 May 2021

Published online: 26 May 2021

References

1. Barnett MH, Mathey E, Kiernan MC, Pollard JD. Axonal damage in central and peripheral nervous system inflammatory demyelinating diseases: common and divergent pathways of tissue damage. Curr Opin Neurol. 2016;29(3):213-21.

2. Storch M, Lassmann H. Pathology and pathogenesis of demyelinating diseases. Curr Opin Neurol. 1997;10(3):186-92.

3. Takai Y, Misu T, Kaneko K, Chihara N, Narikawa K, Tsuchida S, et al. Myelin oligodendrocyte glycoprotein antibody-associated disease: an immunopathological study. Brain. 2020;143(5):1431-46.

4. Ochi H, Fujihara K. Demyelinating diseases in Asia. Curr Opin Neurol. 2016;29(3):222-8.

5. Steinman L. Immunology of relapse and remission in multiple sclerosis. Annu Rev Immunol. 2014;32:257-81.

6. Hemmer B, Kerschensteiner M, Korn T. Role of the innate and adaptive immune responses in the course of multiple sclerosis. Lancet Neurol. 2015;14(4):406-19.

7. Thompson AJ, Baranzini SE, Geurts J, Hemmer B, Ciccarelli O. Multiple sclerosis. Lancet. 2018;391(10130):1622-36.

8. Chu F, Shi M, Zheng C, Shen D, Zhu J, Zheng X, et al. The roles of macrophages and microglia in multiple sclerosis and experimental autoimmune encephalomyelitis. J Neuroimmunol. 2018:318:1-7.

9. Glatigny S, Bettelli E. Experimental Autoimmune Encephalomyelitis (EAE) as animal models of multiple sclerosis (MS). Cold Spring Harb Perspect Med. 2018;8(11):a028977.

10. Simmons SB, Pierson ER, Lee SY, Goverman JM. Modeling the heterogeneity of multiple sclerosis in animals. Trends Immunol. 2013;34(8):410-22.

11. Hoftberger R, Guo Y, Flanagan EP, Lopez-Chiriboga AS, Endmayr V, Hochmeister $\mathrm{S}$, et al. The pathology of central nervous system inflammatory demyelinating disease accompanying myelin oligodendrocyte glycoprotein autoantibody. Acta Neuropathol. 2020;139(5):875-92.

12. Lassmann $\mathrm{H}$. The changing concepts in the neuropathology of acquired demyelinating central nervous system disorders. Curr Opin Neurol. 2019;32(3):313-9.

13. Kunkl M, Frascolla S, Amormino C, Volpe E, Tuosto L. Thelper cells: the modulators of inflammation in multiple sclerosis. Cells. 2020;9(2):482.

14. Segal BM. The diversity of encephalitogenic CD4+T cells in multiple sclerosis and its animal models. J Clin Med. 2019;8(1):120.

15. Yasuda K, Takeuchi Y, Hirota K. The pathogenicity of Th17 cells in autoimmune diseases. Semin Immunopathol. 2019;41 (3):283-97.

16. Cheng Y, Sun L, Xie Z, Fan X, Cao Q, Han J, et al. Diversity of immune cell types in multiple sclerosis and its animal model: Pathological and therapeutic implications. J Neurosci Res. 2017;95(10):1973-83.

17. Pierson E, Simmons SB, Castelli L, Goverman JM. Mechanisms regulating regional localization of inflammation during CNS autoimmunity. Immunol Rev. 2012;248(1):205-15.

18. Broux B, Markovic-Plese S, Stinissen P, Hellings N. Pathogenic features of CD4+CD28- $T$ cells in immune disorders. Trends Mol Med. 2012;18(8):446-53.

19. Kleinewietfeld $M$, Hafler DA. Regulatory T cells in autoimmune neuroinflammation. Immunol Rev. 2014;259(1):231-44.

20. Jonas S, Izaurralde E. Towards a molecular understanding of microRNAmediated gene silencing. Nat Rev Genet. 2015;16(7):421-33.

21. Rupaimoole R, Slack FJ. MicroRNA therapeutics: towards a new era for the management of cancer and other diseases. Nat Rev Drug Discov. 2017;16(3):203-22.

22. Mendell JT. miRiad roles for the miR-17-92 cluster in development and disease. Cell. 2008;133(2):217-22.

23. Olive V, Li Q, He L. mir-17-92: a polycistronic oncomir with pleiotropic functions. Immunol Rev. 2013;253(1):158-66. 
24. Mogilyansky E, Rigoutsos I. The miR-17/92 cluster: a comprehensive update on its genomics, genetics, functions and increasingly important and numerous roles in health and disease. Cell Death Differ. 2013;20(12):1603-14.

25. Jiang S, Li C, Olive V, Lykken E, Feng F, Sevilla J, et al. Molecular dissection of the miR-17-92 cluster's critical dual roles in promoting Th1 responses and preventing inducible Treg differentiation. Blood. 2011;118(20):5487-97.

26. Xiao C, Srinivasan L, Calado DP, Patterson HC, Zhang B, Wang J, et al. Lymphoproliferative disease and autoimmunity in mice with increased miR-17-92 expression in lymphocytes. Nat Immunol. 2008;9(4):405-14.

27. Wu Y, Schutt S, Paz K, Zhang M, Flynn RP, Bastian D, et al. MicroRNA-17-92 is required for T-cell and B-cell pathogenicity in chronic graft-versus-host disease in mice. Blood. 2018;131(17):1974-86.

28. Wu Y, Heinrichs J, Bastian D, Fu J, Nguyen H, Schutt S, et al. MicroRNA-17-92 controls T-cell responses in graft-versus-host disease and leukemia relapse in mice. Blood. 2015;126(11):1314-23.

29. Ingwersen J, Menge T, Wingerath B, Kaya D, Graf J, Prozorovski T, et al. Natalizumab restores aberrant miRNA expression profile in multiple sclerosis and reveals a critical role for miR-20b. Ann Clin Transl Neurol. 2015;2(1):43-55

30. Meira M, Sievers C, Hoffmann F, Rasenack M, Kuhle J, Derfuss T, et al. Unraveling natalizumab effects on deregulated miR-17 expression in CD4+ T cells of patients with relapsing-remitting multiple sclerosis. J Immunol Res. 2014;214:897249.

31. Keller A, Leidinger $P$, Steinmeyer F, Stahler C, Franke A, Hemmrich-Stanisak $G$, et al. Comprehensive analysis of microRNA profiles in multiple sclerosis including next-generation sequencing. Mult Scler. 2014;20(3):295-303.

32. Lindberg RL, Hoffmann F, Mehling M, Kuhle J, Kappos L. Altered expression of miR-17-5p in CD4+ lymphocytes of relapsing-remitting multiple sclerosis patients. Eur J Immunol. 2010:40(3):888-98.

33. Gandhi R, Healy B, Gholipour T, Egorova S, Musallam A, Hussain MS, et al. Circulating microRNAs as biomarkers for disease staging in multiple sclerosis. Ann Neurol. 2013;73(6):729-40.

34. Dolati S, Aghebati-Maleki L, Ahmadi M, Marofi F, Babaloo Z, Ayramloo $\mathrm{H}$, et al. Nanocurcumin restores aberrant miRNA expression profile in multiple sclerosis, randomized, double-blind, placebo-controlled trial. J Cell Physiol. 2018;233(7):5222-30.

35. Liu SQ, Jiang S, Li C, Zhang B, Li QJ. miR-17-92 cluster targets phosphatase and tensin homology and Ikaros Family Zinc Finger 4 to promote TH17mediated inflammation. J Biol Chem. 2014;289(18):12446-56.

36. Jager A, Dardalhon V, Sobel RA, Bettelli E, Kuchroo VK. Th1, Th17, and Th9 effector cells induce experimental autoimmune encephalomyelitis with different pathological phenotypes. J Immunol. 2009;183(11):7169-77.

37. Lee PW, Severin ME, Lovett-Racke AE. TGF- $\beta$ regulation of encephalitogenic and regulatory $T$ cells in multiple sclerosis. Eur J Immunol. 2017:47(3):446-53.

38. Kang SG, Liu WH, Lu P, Jin HY, Lim HW, Shepherd J, et al. MicroRNAs of the miR-17 approximately 92 family are critical regulators of $\mathrm{T}(\mathrm{FH})$ differentiation. Nat Immunol. 2013;14(8):849-57.

39. Qin HH, Zhu XH, Liang J, Wu JF, Yang YS, Xu JH. The expression and significance of miR-17-92 cluster miRs in CD4 (+) T cells from patients with systemic lupus erythernatosus. Clin Exp Rheumatol. 2013;31(3):472-3.

40. Akhtar N, Singh AK, Ahmed S. MicroRNA-17 Suppresses TNF-alpha Signaling by Interfering with TRAF2 and CIAP2 Association in Rheumatoid Arthritis Synovial Fibroblasts. J Immunol. 2016;197(6):2219-28.
41. Cox MB, Cairns MJ, Gandhi KS, Carroll AP, Moscovis S, Stewart GJ, et al. MicroRNAs miR-17 and miR-20a inhibit T cell activation genes and are under-expressed in MS whole blood. PLoS ONE. 2010;5(8):e12132.

42. Keller A, Leidinger $P$, Steinmeyer F, Stähler C, Franke A, Hemmrich-Stanisak $\mathrm{G}$, et al. Comprehensive analysis of microRNA profiles in multiple sclerosis including next-generation sequencing. Mult Scler. 2014;20(3):295-303.

43. Ehtesham N, Khorvash F, Kheirollahi M. miR-145 and miR20a-5p potentially mediate pleiotropic effects of interferon-beta through mitogenactivated protein kinase signaling pathway in multiple sclerosis patients. J Mol Neurosci. 2017;61(1):16-24.

44. Ghadiri N, Emamnia N, Ganjalikhani-Hakemi M, Ghaedi K, Etemadifar M, Salehi M, et al. Analysis of the expression of mir-34a, mir-199a, mir-30c and mir-19a in peripheral blood CD4+T lymphocytes of relapsing-remitting multiple sclerosis patients. Gene. 2018;659:109-17.

45. Jin S, Sun S, Ling H, Ma J, Zhang X, Xie Z, et al. Protectin DX restores Treg/ Th17 cell balance in rheumatoid arthritis by inhibiting NLRP3 inflammasome via miR-20a. Cell Death Dis. 2021;12(3):280

46. Chang R, Yi S, Tan X, Huang Y, Wang Q, Su G, et al. MicroRNA-20a-5p suppresses IL-17 production by targeting OSM and CCL1 in patients with Vogt-Koyanagi-Harada disease. Br J Ophthalmol. 2018;102(2):282-90.

47. Durkin JT, Holskin BP, Kopec KK, Reed MS, Spais CM, Steffy BM, et al. Phosphoregulation of mixed-lineage kinase 1 activity by multiple phosphorylation in the activation loop. Biochemistry. 2004;43(51):16348-55.

48. Gallo KA, Johnson GL. Mixed-lineage kinase control of JNK and p38 MAPK pathways. Nat Rev Mol Cell Biol. 2002;3(9):663-72.

49. Marusiak AA, Edwards ZC, Hugo W, Trotter EW, Girotti MR, Stephenson NL, et al. Mixed lineage kinases activate MEK independently of RAF to mediate resistance to RAF inhibitors. Nat Commun. 2014;5:3901.

50. Kim EK, Choi EJ. Compromised MAPK signaling in human diseases: an update. Arch Toxicol. 2015;89(6):867-82.

51. Bao R, Hou J, Li Y, Bian J, Deng X, Zhu X, et al. Adenosine promotes Foxp3 expression in Treg cells in sepsis model by activating JNK/AP-1 pathway. Am J Transl Res. 2016;8(5):2284-92.

52. Lu L, Ma J, Wang X, Wang J, Zhang F, Yu J, et al. Synergistic effect of TGF-beta superfamily members on the induction of Foxp3+Treg. Eur J Immunol. 2010;40(1):142-52.

53. He T, Liu S, Chen S, Ye J, Wu X, Bian Z, et al. The p38 MAPK inhibitor SB203580 abrogates tumor necrosis factor-induced proliferative expansion of mouse CD4 (+)Foxp3 (+) regulatory T cells. Front Immunol. 2018;9:1556.

54. Adler HS, Kubsch S, Graulich E, Ludwig S, Knop J, Steinbrink K. Activation of MAP kinase p38 is critical for the cell-cycle-controlled suppressor function of regulatory T cells. Blood. 2007;109(10):4351-9.

55. Sun P, Liu DZ, Jickling GC, Sharp FR, Yin KJ. MicroRNA-based therapeutics in central nervous system injuries. J Cereb Blood Flow Metab. 2018;38(7):1125-48.

\section{Publisher's Note}

Springer Nature remains neutral with regard to jurisdictional claims in published maps and institutional affiliations.

Ready to submit your research? Choose BMC and benefit from

- fast, convenient online submission

- thorough peer review by experienced researchers in your field

- rapid publication on acceptance

- support for research data, including large and complex data types

- gold Open Access which fosters wider collaboration and increased citations

- maximum visibility for your research: over $100 \mathrm{M}$ website views per year

At $\mathrm{BMC}$, research is always in progress.

Learn more biomedcentral.com/submissions 